\title{
The Unification of Didactic Transposition Theory with the Didactic Situation Theory of Brousseau
}

\author{
Luiz Adolfo de Mello \\ Physics Department, Universidade Federal de Sergipe, Sergipe, Brazil
}

\section{Email address:}

ladmello@ufs.br

\section{To cite this article:}

Luiz Adolfo de Mello. The Unification of Didactic Transposition Theory with the Didactic Situation Theory of Brousseau. Teacher Education and Curriculum Studies. Vol. 4, No. 4, 2019, pp. 65-75. doi: 10.11648/j.tecs.20190404.12

Received: November 26, 2019; Accepted: December 21, 2019; Published: February 10, 2020

\begin{abstract}
We present the most current version of the theory of didactic transposition that encompasses and synthesizes the theory of Chevallard, the Cognitive Theory of Science, Mental Models of Jhonson-Laird and Didactic Situation theory of Brousseau. It is made here a brief review of Chevallard theory and exposes the generalization of this theory by the De Mello according to the work of Izquierdo-Aymerich and the Brousseau. It is proposed here a theory to study how the scientific knowledge (the original scientific models) is transposed to the didactic models. That is, to analyze how the knowledge produced in the 'academic environment' change, adapt, simplify and consolidate as knowledge to be taught in the classroom. We present the characteristics that define the reason for certain knowledge to be present in textbooks as defined in the work of Chevallard, Brockington and others and complementing their work we propose rules that define how a DT should occur or be performed. We present Brousseau's theory for didactic transposition in the classroom or intern, that is, what he calls the didactic contract and didactic situation. Here are proposed particular rules for the science of Mathematics, Physics and Chemistry.
\end{abstract}

Keywords: Didactic Transposition, Scientific Paradigm, School Scientific Activity, The Textbook Analysis, Didactic Situation

\section{Introduction}

Within the context of editorial policies, national programs of textbooks production and formulation of public policies it is very important to understand how scientific knowledge is transposed or translated to textbooks and how this is actually taught in the classroom. The scientific theory that addresses this problem is called the Didactic Transposition (DT). As will be explained later, it would not be possible to create some general guidelines on how to transpose or translate to school level scientific or academic knowledge for all exact sciences. Thus, we will present here some guidelines on how DT should occur for physics and chemistry on the one hand, and on the other for the science of mathematics.

We present here the current form of the theory of Didactic Transposition (DT) that is denominate Theory of Didactic Transposition of Chevallard, Izquierdo-Aymerich and De Mello (DT-CHIM). Originally the theory of DT was conceived by Chevallard [1] as a way to analyze how the knowledge produced in scientific spheres is translated to the school levels
- basic cycle. The Chevallard's theory of DT is focused on socio-cultural aspects of how the transformation of knowledge occurs and not in the semantics and epistemological aspect of this. Note that Chevallard [2] and others address various epistemological problems in mathematics teaching or its DT, but as examples of didactic system intervention and not as general rules of how DT should occur.

As highlighted by Halté [3], Chevallard elaborated his "theory" in journalistic form. That is, in the form of a description of how the scientific community and educators transform academic into school knowledge. It defines some of the reasons why certain knowledge is transposed into the educational environment and provides some reasons why this becomes permanent or obsolete over time. Halté goes further in discussing the fact that the problem of DT involves much more than just the knowledge. As Halté [3] states:

The notion of scientific knowledge designates only the object of the mechanisms of transposition and does not question the mechanisms themselves and the role of actors, scientists, students, teachers, and others in this transformation. 


\section{The Theory of Didactic Transposition and the Didactic Contract of Brousseau}

\subsection{The Theory of Didactic Transposition of Chevallard}

Despite its descriptive and conceptual character, this theory has become a subject of knowledge and theoretical reference for several pedagogical theories as stated by Haltè [3]. The survival and revitalization of this theory is due to the fact that it is the first attempt to define school knowledge, differentiate it from academic knowledge and classify these forms of knowledge. The Chevallard theory of DT deals with the problem to understand, classify and study how the knowledge produced in the research spheres will be adjusting, adapting and transforming into scientific knowledge taught in the classroom.

For this Chevallard [1] classifies the knowledge in three categories. Research knowledge which he calls the Scholar Knowledge; He named the knowledge contained in the textbooks as the Knowledge to be Taught; The knowledge as taught in the classroom as the Knowledge Taught. See figure 1. The ideas and concepts developed by Chevallard [1] were developed to study the passage of the "knowledge" from the research environment to the basic cycle of education. Due to the French university structure in his didactic transposition model he does the simplification that the research environment is unique, despite this point out that DT begins to occur in academic circles. Namely, that the knowledge produced in the research environment is already produced in the final form to be transposed directly to the high school.

But the theory of DT can be applied to the structure of higher education [4] since the transformation of scientific (scholarly) knowledge begins in this sphere of knowledge (or Epistemosphere). So, the theory of DT should consider that the knowledge produced in research spheres (scholar knowledge) is consolidated and/or regulated in the postgraduate programs (sphere), the academic knowledge, then transposed to the level of the Bachelor and finally transcribed or adapted to the level of the basic cycle of education (the Knowledge to be Taught). This is necessary because we have today textbooks designed for postgraduate courses and graduation. Strictly speaking we would have to subdivide the graduation degree in academic and university basic level cycle [4], so we have to divide the Scholar Knowledge into three parts. Research Knowledge (Research Level), the Academic Knowledge (Post-graduation Level) and the University Knowledge (graduate level).

Then we have now five levels of presentation or transcription of knowledge. The level: 1) Research; 2) Postgraduate; 3) senior and 4) junior years of Bachelor and finally 5) basic education.

Following the Chevallard notation we have:

Research Knowledge $\rightarrow$ Academic Knowledge $\rightarrow$ University Knowledge $\rightarrow$ Knowledge to be Taught $\rightarrow$
Knowledge Taught

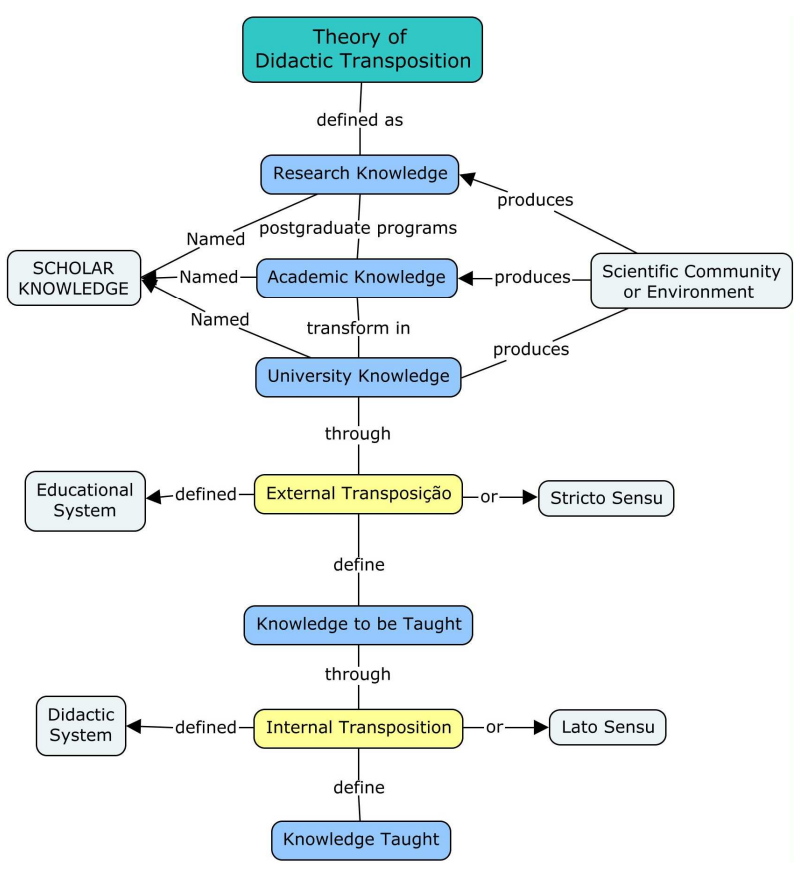

Figure 1. Theory of Didactic Transposition after Brousseau.

Chevallard [2] discriminates the DT theory in external DT or Lato Sensu and internal DT or Stricto Sensu, figure 1. Chevallard focuses his studies on describing the external transposition. That is, which mechanisms and actors participate in the process of transforming academic knowledge to the textbook or didactic guidelines. Chevallard as de Mello were not concerned with how this knowledge (the knowledge to be taught) turned into the "taught knowledge" in the classroom. Here we will address and approach this distinction and briefly address internal DT mainly from the perspective of the concepts of pedagogical and didactic contract and didactic situations according to Brousseau [5,6]. That is, let's briefly summarize Brousseau's ideas and teaching methodologies applied in the classroom. As you will see below, Brousseau makes a more detailed study of internal DT, but, like Chevallard, his theory is descriptive rather than a teaching methodology.

The DT theory affirms that we only can understand how scientific knowledge is transcribed to textbooks if we include in their analysis the external environment in which it occurs. This transformation occurs within a university environment (the Didactic System), that is, inside a small universe that is the external environment (the educational system). In addition to these environments we have the school environment where effectively occurs the DT. That is, we have to take into account that there are factors outside the school system that influence the DT process [7].

To designate the participating elements that regulate the selection and determination of the modifications that research knowledge will undergo until become school knowledge Chevallard [8] created the word noosphere. The noosphere is composed of scientists, educators, teachers, politicians, authors of textbooks, among others [7]. Due to the diversity 
and richness of existing factors in the academic sphere governing the selection and standardization of scientific knowledge De Mello called this environment epistemosphere [4].

Within this epistemosphere we have, in the case of exact courses, Physics books written for courses based on calculus and the other based on algebra. We have Conceptual Physics books, Physics for Engineers and traditional. The equivalent of the mathematical discipline would be the textbooks designed specifically for engineering courses as opposed to those used in bachelor degree mathematics courses. And the mathematics books for business and economics courses. De Mello $[9,10]$ demonstrated that DT for the basic cycle occurs from these texts and not from the original articles. Thus a theory of DT should study and track how the knowledge or scholar Knowledge is transformed in this epistemosphere to become the Knowledge to be Taught.

After this phase, the knowledge is transformed within the context of editorial policies, national programs of textbooks production and formulation of public policies to achieve the textbooks and be effectively taught in the classroom. Is here that the teaching methodologies and pedagogical proposals come into play. That is, when studying or analyzing the transformations that knowledge suffers to reach the school environment we should consider both the epistemological aspects of science as their pedagogical and methodological aspects of teaching.

Like every theory of human and social sciences, the DT theory does not contain "closed" laws or rules defining as a DT should occur or be achieved. But even so, Chevallard proposed some characteristics that define the reason that a certain knowledge to be present in textbooks. Chevallard [1] defines some of these characteristics. In summary these are [7]:

1st - Consensual: The Noosphere members must agree that a given knowledge is definitely established. That is, it is not speculative or that there is no doubt in the scientific community.

2nd - Moral Actuality: The Noosphere members must agree that a given knowledge is relevant and necessary in order to be entered or remain in the school curriculum.

3rd - Biological Actuality: The content taught should be consistent with the theories or current models or accepted by the scientific community. While this is seemingly obvious, there are pedagogical exceptions. For example, we have the fact that Thomson, Rutherford and Bohr models are still being taught in schools.

4th - Operationality: For a knowledge be implemented and remain in school curriculums this should generate questions, exercises and problems. As an example we have all the textbooks discuss in detail the theory of the photoelectric effect and on the other hand few address in detail the theory of blackbody radiation.

5th - Teaching Creativity: Chevallard has coined this term to be able to explain the reason to teach subjects of science that are currently not part of the research field.

6th - Therapeutic: One of the reasons a particular knowledge to stay in school curricula is to your success in the classroom.

Due to the great scientific and technological advances, and needs of the school curriculum updating, Chevallard [8] has produced five rules for DT [11]. We will list below only their first two, which from our point of view fit within this classification, that is:

7th - Modernizing school knowledge. The curriculum should address current subjects, such as: a) superconductivity; b) nanotechnology; etc.

8th - Update the knowledge to teach. The noosphere agents must define what knowledge should be removed from textbooks because they are obsolete.

From our point of view the fourth Astolfi rule [12] is included in the guideline 4 (Operationality) of Chevallard. And the rules 3 and 5 fall into guidelines or suggestions on how the DT should be made. With these 8 rules Chevallard defines the External Didactic Transposition. To go further we have to define the internal DT, that is, we need to study the theory of didactic situations and Brousseau's didactic contract.

\subsection{Inner Didactic Transposition}

After educators, textbook writers, and decision-makers in education departments decide what should be taught in the classroom, it is up to the teacher to decide how these norms and content will be effectively operationalized in the classroom. In the case of propaedeutic or banking learning methodologies [13] the teacher is the holder of knowledge and the students must listen and operationalize what the teacher teaches. In this type of teaching methodology there is only relationship between the teacher and the students, and this is the subservience of the students. In the other methodologies besides the students dialog with the teacher, they also interact with the knowledge. For this the teacher must create a special learning environment that Brousseau [5] coined the term milieu. Thus, for each teaching methodology the teacher must prepare the most appropriate milieu for this. For example: computer room, lab room, play room, etc.

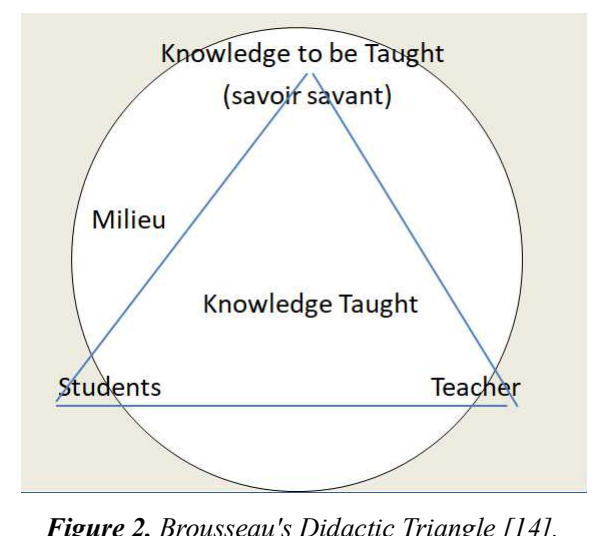

\subsection{The Didactic Situation}

As in active and discovery learning methodologies the teacher is not merely a transmitter of knowledge and the 
students the receptors. The knowledge taught occurs within a relationship between three subjects: teacher, students and knowledge. These relationships are determined by the teaching methodology used. The relationship between knowledge and teacher occurs both in class preparation and in the way the teacher administers or governs the class. The knowledge-student relationship occurs at the moment before, during and after class and is largely governed by the teaching methodology used in class. In class this relationship is governed by the milieu prepared by the teacher. In Just'in Time Teaching this relationship is mediated by clicks and formations of discussion's double; in project-based learning, this relationship is mediated by the formation of research groups and project objectives, and so on. The student-teacher relationship is determined by the teaching methodology employed. See figure 3.

In didactics of mathematics Brousseau is concerned with creating an artificial school environment that mimics an academic environment.

In addition, he wants that this environment create conditions for students to feel motivated to make mathematical discoveries. These can occur through games, problems and business situations, as in the case of market games.

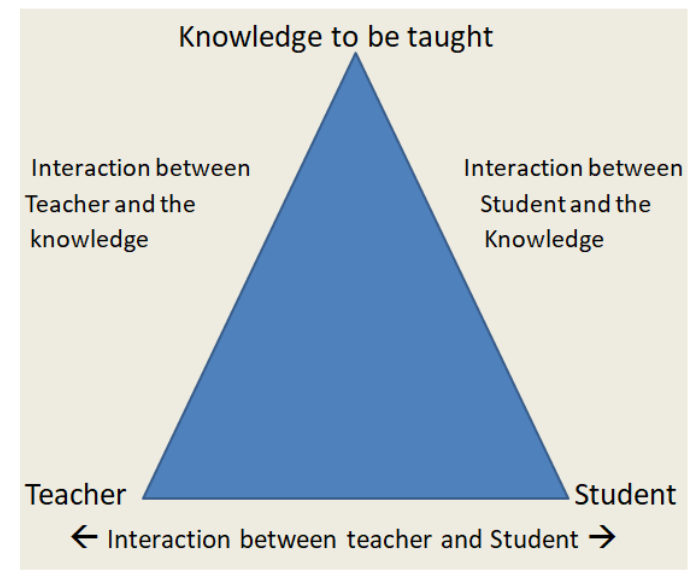

Figure 3. Pedagogical Triangle [15].

Brousseau calls these relationships "Didactic Situations." For Brousseau, the didactic situation consists of:

(...) a set of explicit or implicit relationships that establish a student or group of students, an environment (including eventually instruments or objects), and an educational system (represented by the teacher) which aims is make these students take possession of a knowledge already constituted or in the process to be constituted [16].

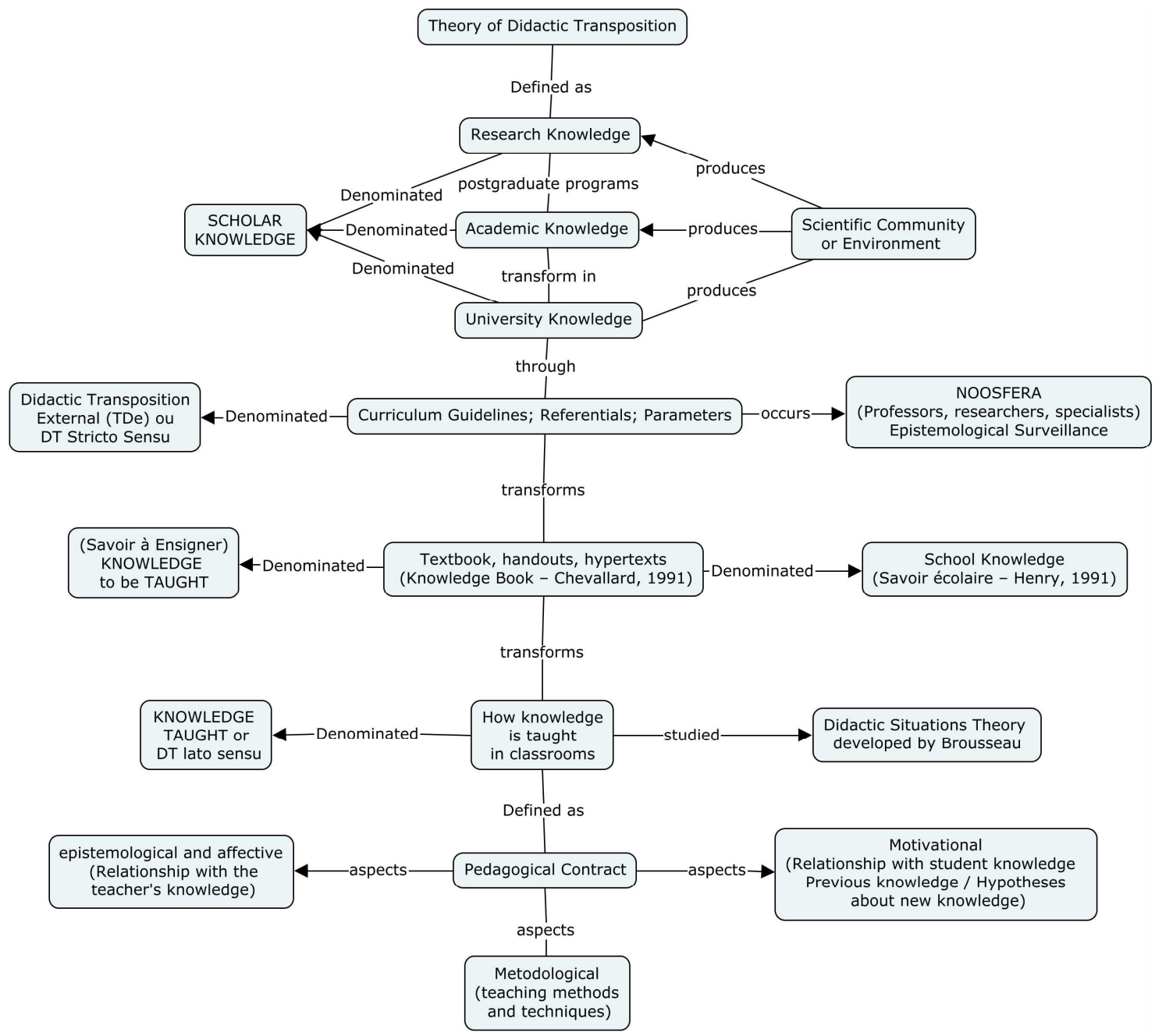

Figure 4. The Theory of Didactic Transposition plus the Didactic Contract. 
Brousseau realized that the milieu is also an integral part of the pedagogical project. Thus, Brousseau [16] admits the existence of a system of interactions, but identifies other factors interacting in the system: the material and school environment and the educational system. Depending on the environment the teacher will have a teaching milieu - school, private or public school system. In addition, it indicates two more factors: the interaction between the system and the student / learner person. That is, the student person interacting with the rules of the education system, and the learner person as a subject who interacts with the teacher and knowledge [14]. See figure 4.

\subsection{Didactic Contract}

From his classroom experience and observations of students' general behavior in relation to the school system, Brousseau realizes that there is subliminally a contract or pact (a pre-established relationship) between the partners or actors in a class. He has denominated it as didactic contract. Even in the propaedeutic (traditional classes) case there is an implicit didactic contract, that is, students should listen to the teacher, write down the lessons, study and make the tests. Even in the methodology of learning by discovery it is the teacher with the endorsement of the educational institution that prepares and administers the didactic sequences and the milieu so that the student seizes the knowledge by himself. In the Just'in Time Teacher methodology this contract is very explicit. Students are informed and encouraged to read instructional material before class, under the external stimulus of grade assignments, and to form peer group discussions during class.

Broussaeu formalizes the existence of this contract, from now on called the didactic contract and defines it descriptively. As pointed out by several authors [3, 17] French researchers in Mathematics Didactics have intensively discussed the concept of didactic contract and describe it as follows:

The student and the teacher do not occupy symmetrical positions in relation to knowledge. The second not only "knows" more than the first, but has the responsibility to organize the teaching situations considered favorable for the first's learning. Being able to deal with the eventual common structure of these situations while at the same time their diversity, their different characteristics, their scope and subsequent limitations lead to a decisive clarity of the didactic acts [18].

The idea of a didactic contract was evolving to such an extent that it became an integral part of the didactic system and didactic (internal) transposition. See figure 4.

\section{Results}

\subsection{The Theory of Didactic Transposition of Chevallard, Izquierdo and De Mello (DT-CHIM)}

It can be shown that as knowledge is transformed, updating and adapting to a certain level of knowledge their explanatory models will be adjusting to the knowledge level of the target audience and to the current scientific paradigm. De Mello demonstrated that due to scientific theories be developed through concepts, called nodes or links by Latour [10], the conceptual mapping is the natural and most appropriated tool to perform this analysis $[4,9,10]$.

As mentioned in the literature [10] with the expansion of the publishing market we have today a relative variety of textbooks produced within this epistemosphere. This created the possibility and the need to produce new proposals for education. Currently, we have research that point to the fact that one should take into account the design characteristics of presentation of knowledge [19, 51]. This production generated a certain amount of textbooks with features, methodologies and specific objectives. Thus the theory of DT should cover their socio-cultural, epistemological, semantic and editorial aspect.

Then briefly the Generalized Didactic Transposition Theory (DT-CHIM) is a theory that involves the epistemology of science, cognitive science theory, didactic of the education and social theories to understand, create rules and study the mechanisms that conduct the process of transformation of knowledge produced in the research spheres to the academic field, and from this to textbooks and from this to the classroom of high school. That is, research groups choose the content to be taught in postgraduate courses, and the undergraduate committees and departments of education select the content to be taught at the basic levels of education. Over time these contents are being consolidated and legitimized and sealed in textbooks - Latour thesis [20]. Such a packaging process leaves out details, explanations, and reasons that were previously necessary to convince others of their "original power to explain" - both scientifically and didactically [21].

De Mello [9] demonstrates, for the case of the topic of physics called Photoelectric Effect, that currently the scientific knowledge is structured didactically in their transcriptions to textbooks in: a) models; b) the core of the theory; c) experimental facts; d) the key concepts; e) the methodology and $f$ ) the application of the theory. Thus, it is necessary to understand how these "pieces of knowledge" are inserted, deleted, and summarized to make each text a coherent whole.

De Mello [4, 9] divides the theory of DT into two parts. One part of the theory deals with the socio-cultural influences on didactic teaching [7, 21]. And the other is concerned with the epistemological and semantic aspects of the theories and how these are translated to the textbooks [4, $9,10]$.

\subsection{Didactic Transposition and the Cognitive Model of Science}

Recent contributions from epistemology of science for science teaching led to a new approach (theory) of the latter called "cognitive model of science" (CMS) [21] that 
originates from Kuhn's philosophy of science [22]. Along with the theory of "didactic transposition" suggest the possibility to analyze with more depth as knowledge produced in scientific spheres is translated to the school sphere.

To understand how the knowledge produced in research spheres (scholar knowledge) is transposed to the school spheres we should take into account what is actually meant by scientific knowledge and to do science in the educational system or educational environment.

When researchers disclose their research in the form of articles, they present their findings and conclusions based on theories and research methodologies that cannot always be explained directly, without suffering a DT, to students in general. In research groups, doctoral and masters students are trained in applying their academic knowledge to theoretical and experimental methods and then disseminating them academically.

So, in the scientific spheres, teach science is teach systems or methods of acquiring knowledge and at the same time teach how to arrive to this organized body of knowledge from them. But in general it is impossible to reproduce in the classroom [23]. Thus, the question arises: What is taught science in high school classroom as in the university?

According to Izquierdo-Aymerich $[21]^{1}$ when we define with didactic purposes what is science or to do science, translating or simplifying it to the student level, we can describe it as a way of thinking and acting in order to interpret certain phenomena and to intervene through a series of theoretical and practical structured knowledge. As a result of science education is desirable that students understand that the natural world has certain characteristics that can be modeled theoretically, that is, to be described as laws or scientific models. Because of this we present to them, making a DT, some reconstructed facts, theoretical models, arguments and propositions that were previously selected. This is the natural science version of milieu of Brousseau [16].

In addition, if the teaching of sciences is done in accordance with the principles of meaningful learning [24], that is, a well executed didactic transposition [2], the teachers will be involved in the task of connect scientific models to used by pupils themselves, using analogies and metaphors that may help them to move from the last for the first [25-28].

If we analyze the textbooks written for high school, from the point of view of knowledge and its method of obtaining, we see that these are classified into two types: a) those who start exposing the theory and then presenting the experimental facts that leads to its formulation or discovery as a mere confirmation of its validity or importance. b) and those that begin exposing the experimental facts that resulted in its formulation and putting the theory as a direct consequence of these facts. With the introduction of modern

1 The following two paragraphs are a collection of statements that together form the definition of that is the DT from the CTS point of view. methods of teaching we have some alternative versions of exposure of textbooks. For example, we have textbooks written in the problem-based learning [29] in which each topic is preceded and motivated by the presentation of a puzzle that contextualizes the need of the search or theory formulation.

Based on the above ideas and within the current context of science education in the basic cycle and university we can suggest some guidelines for how the DT should be made.

9th - Partition of knowledge: Divide into its constituent parts, that is, between theory, model, experimental facts, applications, historical facts, etc.

10th - Articulate the "new" knowledge with the "old" [8]: When teaching a new theory, such as special relativity, the author and/or teacher should make clear that the old theory (in this case the classical mechanics) is still valid within their limits of validity (at low speeds).

11th - Make a concept understandable [8]: We must rewrite or redraft a concept to the level of students understanding.

12th - Making a model significant: To adapt and/or modify the theoretical models, or the scientific models to the level of students understanding. Or connect it to the model used by them.

13th - Simple Math: Scientific knowledge should be redrafted using an appropriate mathematical formalism to every school level.

14th - Pedagogical Actuality: Scientific knowledge must be redrafted in accordance with a teaching methodology. For example, according to the methodology of problem-based learning or be designed as a significant potential teaching unit.

15th - Functional Actuality: Scientific knowledge should be drawn up according to the type of training required for each course. For example, text to train engineers.

To justify the introduction of 14 and 15 guidelines we currently have several university courses with various educational proposals. Some proposes to train scientists in general and others to train professionals for the labor market. A line of educators argue that science education should somehow reflect what scientific activity is and do science. But others argue that science should be taught in an objective manner. That is, it should be taught the concepts, theories and applications without worrying about whatever it is do science. Thus, the science teaching at school cannot be strictly based on the analogy of the student as a future scientist, that is, with a strong scientific basis [21].

In the first line Izquierdo-Aymerich and Aduriz Bravo [21] distinguishes between the characteristics of two sciences, the science of scientists and what they call school science. They argue that both sciences have a common cognitive goal: understand the world and communicate theoretical ideas accurately and significantly. Moreover, they propose that the didactic transposition process consists in recreate the science of scientists in the classroom, according to their own institutional values, rhetorical tools and educational goals, to convert it into school science. 


\subsection{Mental Models}

To justify the introduction of the guideline 13 we have the fact that many authors [30-33] defend the idea that the students to think about a scientific fact do not use scientific models, but mental models. This cognitive fact originates a research field called alternative or previous conceptions [34]. Thus, for a given knowledge to be transposed pedagogically, that is, according to the most current knowledge of science education, this should take into consideration how scientific models must be connected to the students models, ensuring meaningful learning [24].

But what would be these models used by the students and for all of us? Without going into details in the various forms or types of reasoning, we have that Johnson-Laird [30] argues that people reason through mental models. In contrast to scientific models created by scientists in order to explain experimental facts, people often use hypothetical models created from their previous experiences, or previous conceptions. Johnson-Laird coined the word mental models for these cognitive structures created in humans by previous conceptions. These mental models represent accurately or not accurately the physical object or event (situation). The most important fact is that its structure is very similar (analogous) to the physical event [35]. For example, we have the alternative conception that a stronger and heavier man pushes a lighter man with more force. But by the law of action and reaction the two exert in modulus the same force.

In other words, mental model is an internal representation of information that corresponds analogously to the state of things that is being represented, whatever it [36].

Analog models are often used to do research, create, test, and communicate ideas [37]. The analogy is an effective way to explain new ideas since the explainer and the listener understands the analogy in the same way. The analogy is call familiar object, experience or process [32]. Analog explanations work when the explainer and the listener agree with analog mappings that exist between the analog (prior knowledge) and the target (scientific knowledge) and mappings are said to be shared when both parties agree that the analog is similar to target in this or that way.

But there is a basic difference between conceptual and mental models [38]. Physical models are conceptual models, that is, models built by researchers in order to develop his theories and contribute to the understanding and teaching of physical systems. It is an accurate, consistent and complete representations of physical phenomena according to a certain theory [32]. However, the models of the students, or any individual, including those who create conceptual models are mental models, that is, models that people construct to represent states of physical things (as well as states of abstract things) through their common experiences. [31, 32, 36].

As an example we have the atomic model. Depending on the level of education when we ask what would be the atomic model we would have a different answer. The model of Thompson, the Bohr or Quantum Mechanics. Thus, there is not a single mental model for a given state of things. On the other way, there may be several models, even if only one of them represents accurately this state of things. Each mental model is an analog representation of this state of things and, conversely, each analog representation corresponds to a mental model [36].

\subsection{Didactic Transposition of Mathematical Knowledge}

In the same manner that the just reading of an article or encyclopedia we will never have any idea what "science Music" is as it is understood by the great geniuses, so too few physicists understand physics as understood by the great geniuses of physics like Albert Einstein, J Clark Maxwell, Isaac Newton, etc. Similarly it would be impossible here to provide a completely general definition of what mathematics would be. Let's look at some definitions found in the literature of what mathematical science would be so that we can justify our choice to define it from the point of view of mathematical didactics scientists and neuropsychologists.

In his exceptional introductory treatise, "What is mathematics?" Courant and Robbins wrote:

Mathematics as an expression of the human mind reflects active will, contemplative reason, and the desire for aesthetic perfection. Its basic elements are logic and intuition, analysis and construction, generalization and individualization. Although different traditions may emphasize different aspects, it is only the interplay of these antithetical forces and the struggle for their synthesis that constitute the life, utility, and ultimate value of mathematical science [39].

From the point of view of mathematics and teaching didactics we have the following question: Is this capacity for perception and logical reasoning available or achievable by anyone? That is, would there be a method of teaching or education that would allow any human being to achieve this goal? The answer is no. For that would imply that all people were completely equal. But not all people are willing, by intrinsic motivation, to make the effort and to have the necessary dedication to obtain the degree of abstraction and the required mathematical reasoning ability.

We would have a more tangible definition of this science. How can we read in Ponte [40]

mathematics can be viewed as a body of knowledge, consisting of a set of well-defined theories (perspective of mathematics as a product)' or as an activity (consisting of a set of characteristic processes). It can be further argued that both product and process are equally important, and only make sense if equated together. It will be impossible in this case to explain to someone what mathematics is without presenting an example in which their own processes are simultaneously used and illustrated with concepts from one of their theories.

P. Ernest states [41]:

Essentially, mathematics should be considered from two points of view: (a) mathematics as a formal and deductive body of knowledge, as set forth in high-level treatises and books; (b) mathematics as a human activity.

Thus mathematics is a scientific knowledge as defined by 
Chevallard [2].

That is, it is a set of knowledge defined in each age that must be appropriated by human beings. But there is a fundamental difference between mathematics and the other sciences. While in the other sciences, even though wellformalized, their theories may be rejected because their conclusions cannot be confronted with experience, mathematics exists on its own. That is, it only depends on the rigor of mathematical reasoning. The precise and formal character of mathematical arguments allows them to resist criticism and are self-sufficient even when they are quite complex [42]. The arguments of the other sciences are also accurate, but since they are subject to confrontation with experience, their character need not be formalized. But what are this mathematical rigor and its formal and precise character?

The central point here is that mathematics is both knowledge and a form of reasoning. Similarly to the principle of wave-particle duality, mathematics is a dual science. It has a body of knowledge - arithmetic, algebra, infinitesimal analysis, probability theory, set theory, topology, differential geometry, functional analysis... but it is built using the rules of logic and mathematical formalism, and it is the tool in which the formal "structure" of all other sciences is constructed. In the other sciences there is at least a statistical analysis corroborating some statements, information and consequences of a given model or theory. Thus we had to create criteria 9, 10 and 11 below for the DT (DT-Math) in order to encompass and characterize the teaching and understanding of this conception of mathematical science.

For the sake of clarity, let us look in reverse order from the point of view of the socio-constructivist mathematicians what would be the mathematical skills or competences of mathematical knowledge [40]. We can distinguish four levels of competencies in mathematical knowledge, according to their function and level of complexity. Thus we will have the elementary, intermediate and complex skills, and the general knowledge (see table 1).

When we study the history of science in general, television or web documentaries lead us to think that general knowledge or this kind of appreciation of mathematics is restricted to a few sages. That this kind of vision (ability) would be more restricted to gifted ones like Isaac Newton, Gauss, Leibnitz, Albert Einstein, etc. This view or appreciation of mathematics would only be achieved by a few. Reading Carl B. Boiler ${ }^{2}$ about Leonhard Euler's life and his role in mathematics we can see from Lagrange's words that anyone who wanted to learn physics should study Euler. That is, the physics as we understand it today is reformulated or that would have undergone a didactic transposition according to Euler's knowledge. Thus even the aesthetic view of science that the great scientists and mathematicians possess depends on the transposition or formalization that other scientists have created. It is not a "gift" or general

2 History of mathematics. ability. That is why the texts on mathematics teaching do not cite or only point these in their introductory notes.

Thus, general knowledge and advanced skills, according to the definition of educators, are only achieved or required by students of the bachelor's degree and postgraduate mathematics courses. They may still be required in other courses in countries such as France, Germany, Russia, etc.

Table 1. Levels of skills in mathematical knowledge - [retrieved from 40].

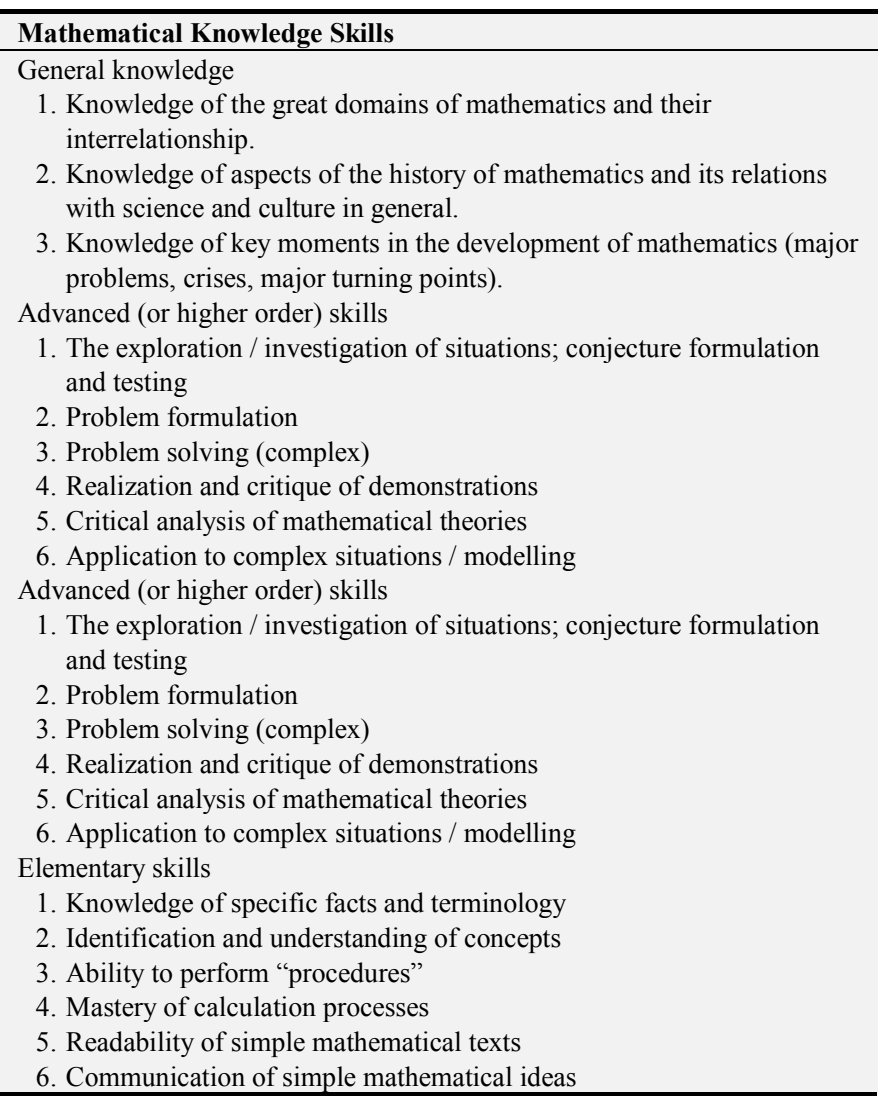

Intermediate and elementary competences, as required by the Program for International Student Assessment (PISA), must be achieved or achieved in the elementary and intermediate cycle of the basic school cycle. From the ranking of this exam we find that most countries are far below this goal. Thus the guidelines and ideas defended here should be understood as such and not as exact laws or facts.

We can see in the description of these competences that there is the random appearance of the words "knowledge", formulation, resolution, analysis, etc. Thus we have people who are working on the task of defining what would be the science called mathematics come up with the key question: Is mathematics a branch of human knowledge or a reasoning tool or technique? The point that we wish to raise is that from the point of view of the philosophy of mathematics we can bring together in their definition all these conceptions, but from the point of view of didactics of mathematics and computer science (information system, Artificial Intelligence, etc.) we should not and cannot mix these views of mathematics. That is, we agree that mathematics itself encompasses a body of knowledge and the development of 
mathematical reasoning. But in mathematics didactics we must be very clear about this distinction.

Finally the 9th guideline is a consequence of the work of Jean Piaget [43] on the stages of development of intelligence or cognitive abilities and of other authors [40, 44-46] on the role of problem solving in understanding and articulating mathematical knowledge in the handling and understanding of mathematical concepts. We can read in NCTM:

Understanding concepts is not limited to knowing their definition - it also requires understanding how these concepts relate to each other and how they can be used in problem solving. In addition, understanding procedures is not only about their application, but also about understanding why they work how they can be used and how their results can be interpreted [47].

In the case of mathematics textbooks we will change the 9th, 10th and 11th guidelines by the following guidelines:

16th - Constructivist Mathematics: One must define the elementary mathematical objects and concepts, then define their elementary properties and operations and then constructively and anthropologically define their complex properties and operations.

17th - Construction of mathematical knowledge: Showing that mathematics is a knowledge that is built and is at the same time a tool. That definitions, axioms, theorems are proved and serve as an intellectual tool for constructing proofs of other axioms and theorems. - In a first stage the tests must be atomized. Provide only one postulate. - In a 2 nd stage other forms of proof or more postulates should be introduced. - In a 3rd stage the students should be left free, in a constructivist manner, to choose how to take the test. See Glencoe [29] program example.

18th - Integration of the algebraic body: When possible, algebra should not be presented as a technique for solving arithmetic problems.

19th - Modeling Knowledge: Showing how mathematical knowledge is used in other sciences.

20th - Visualization of Knowledge: Show, when possible, that there is both an algebraic and a geometrical way of proving an axiom or theorem.

The 20th guideline comes from the finding that we have greater understanding of mathematical concepts when we visualize (mentalize) them. Leaving aside the problem found in the general bibliography of confusing geometric reasoning with intuitive reasoning, we have several authors [48, 49] that defend the idea that, when possible, show the two possibilities of demonstration of a theorem, the algebraic as the geometric one.

Let's look at what Henri Poincare, who lived with Eisntein, Bohrn, and others, says:

It is impossible to study the works of the great mathematicians, or even those of the smallest, without perceiving and distinguishing two opposing tendencies, or rather two entirely different kinds of minds. The only type is above all concerned with logic; To read his works, we are tempted to believe that they have advanced step by step, like a Vauban who pushes the trenches against the enclosure, leaving nothing to chance. The other type is guided by intuition and, in the first blow, makes quick but sometimes precarious conquests, like daring knights of the advanced guard. [50]

He supported his arguments by contrasting the work of several mathematicians, including the famous German analysts Weierstrass and Riemann, relating this to the work of the students:

Weierstrass reduces everything to the point of view of series and their analytical transformations; to put it better, he reduces analysis to a kind of prolongation of arithmetic; You can flip through all his books without finding a picture. Riemann, on the contrary, immediately calls geometry to his aid; each of his conceptions is an image that no one can forget once he has understood its meaning.

Among our students, we notice the same differences; Some prefer to treat their problems by analysis, "others by geometry." The former are unable to 'see in space', the others quickly tire of long calculations and are perplexed.

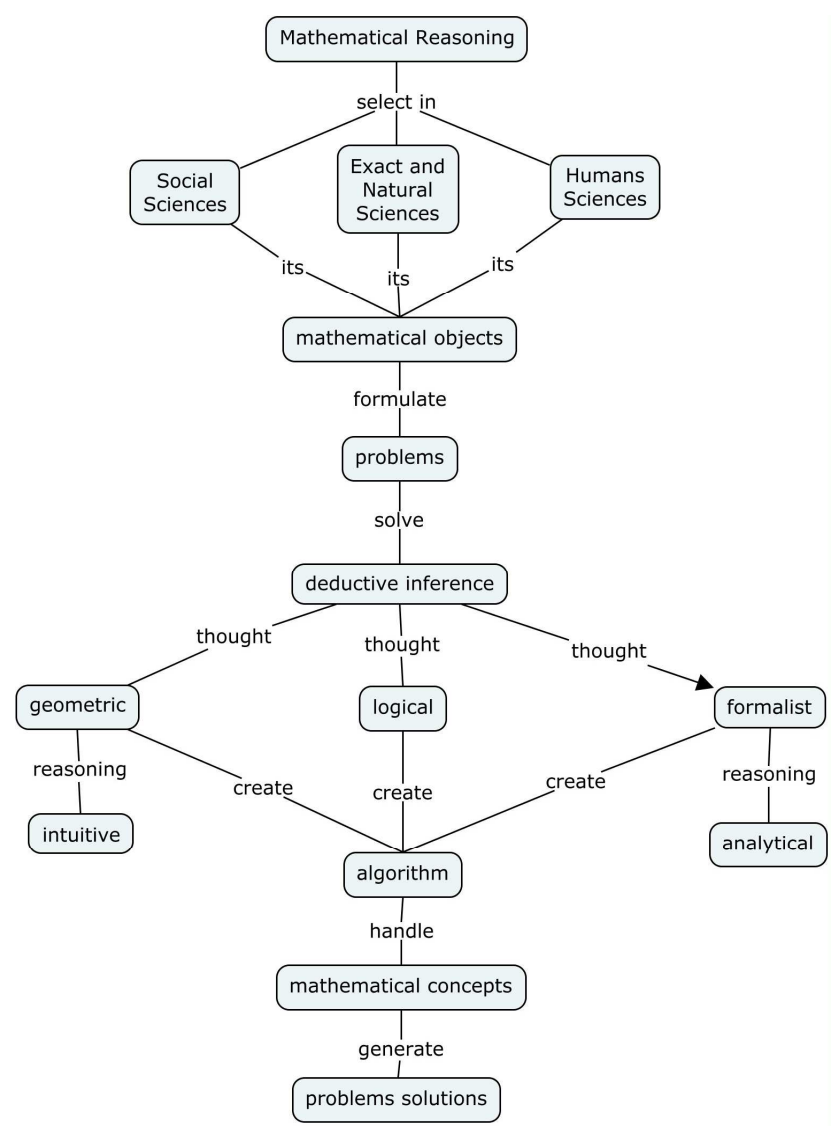

Figure 5. Mathematical Reasoning.

\section{Conclusion}

We presented above an attempt to create rules and standards to study and classify as a DT occur and how would be the ideal DT. A theory (in the broadest sense of its word) initially created to describe the dynamics and transformations that knowledge undergoes or pass until it reaches the halls of the undergraduate cycle through elementary school has 
become a theory that seeks to create rules for how Knowledge must be written or elaborated for didactic purposes. The development and consolidation of active teaching methodologies, like others, have paved the way for the unification of Chevallard's theory of DT with that of Brousseau's didactic situations.

We demonstrate here that although the science of mathematics need not be confronted with experience and that it is a dual science, that is, it is both a body of knowledge and a reasoning tool, we are capable of creating rules for the elaboration of your textbooks. That is, it is possible to create more or less general rules of how their didactic transposition should be made.

Like any field of scientific knowledge, especially human, this is very dynamic and challenging. So these rules should be considered within its scientific and pedagogical actuality. They are based on years of work by researchers as Chevallard, Izquierdo-Aymerich, Pietrocolla, Johnson-Laird, Moreira, Nerssessian, Brousseau and others.

It can be seen here that if we understand well the two phases of the process of didactic transposition, it is clear the possibility of unifying Chevallard's theory of DT and others with the theories of didactical situations and didactic contract of Brousseau's. Although De Mello have achieved prove some of the ideas proposed here through the analysis of textbooks using as tool conceptual mapping, may occur the need to include, replace or reformulate some of these ideas.

\section{Acknowledgements}

We thank SBFísica for the commitment and administration of national professional master's degree in teaching physical (MNPEF), because this work is the result of class preparation of quantum mechanics course to this master's program. We thank CAPES for financing MNPEF and indirectly this work. My sincere thanks to the IHMC by availability of concept maps tools.

\section{References}

[1] Chevalard, Y. La transposición didáctica. Buenos Aires: Aique, 1991.

[2] Chevallard, Y. La Transposición Didáctica: del saber sabio al saber enseñado. La Pensée Sauvage, Argentina, 2009.

[3] Haltè, J. F. (2008) - O Espaço Didático e a Transposição. Fórum Lingüístico, 5 (2): 117-139, Florianópolis.

[4] de Mello. Concept Maps as a Tool for the Evaluation of Modern Physics Contents in Textbooks. Open Science Framework, Retrieved from: <https://osf.io/c376x $>$. Acessed on $05 / 10 / 2016$. $2016 a$.

[5] Brousseau, G. (2004) - Les représentations: étude en théorie des situations didactiques. Revue des sciences de l'éducation, Vol. XXX, no 2, 2004, p. 241 à 277.

[6] Agranionih, N. T. (2001) - A Teoria da Transposição Didática e o Processo de Didatização dos Conteúdos Matemáticos.
Educere - Revista da Educação, Toledo, PR, vol. 1, n-1, pg. 3.

[7] Brockington, G. E. M.; Pietrocola, M. Serão As Regras Da Transposição Didática Aplicáveis Aos Conceitos De Física Moderna? Investigações em Ensino de Ciências - V10 (3), pp. 387-404, 2005.

[8] Chevallard, Y. \& Johsua, M-A. Un exemple d'analyse de la transposition didactique - La notion de distance. Recherches en Didactique des mathematiques. 3.2, 157-239, 1982.

[9] de Mello. Concept Maps as a Tool for the Evaluation of didactic Transposition and of Scientific Transposition. The Case of Photoelectric Effect. Open Science Framework, Retrieved from: <https://osf.io/df97u>. Acessed on: 05/11/2016, 2016b

[10] de Mello. The use of Concepts Mapping in the Science Paradigm Transposition and the Cognitive Science Theory The Case of Black Body Radiation. Open Science Framework, Retrieved from: <https://osf.io/zshkc $>$. Acessed on 05/10/2016, 2016c.

[11] Alves-Filho, J. P. Atividades Experimentais: Do Método á Prática Construtivista. Tese de Doutorado, UFSC, Florianópolis, 2000.

[12] Astolfi, J-P \& Develay, M. A Didática das Ciências. Papirus. Campinas, 1995.

[13] Freire, P. (1997) - Educação como prática da liberdade. Editora Paz e Terra. Rio de Janeiro, 1986.

[14] Aristides, M. A. M. (2018) \& R. M. S. Santos - Contribuição para a Questão das Tecnologias Digitais nos Processos de Ensino-Aprendizagem de Música. Revista da Abem, v. 26, n. 40, p. 91-113, jan./jun. 2018.

[15] Houssaye, Jean. Le triangle pédagogique. Berne: Peter Lang, 1992.

[16] Brousseau, G. (1998). Théorie des situations didactiques. Grenoble, La Pensée Sauvage.

[17] Pinto, N. B. (2003) - Contrato Didático ou Contrato Pedagógico? Revista Diálogo Educacional, Curitiba, v. 4, n. 10, p. 93-106.

[18] Joshua, S. and JJ Dupin - Taking into account student conceptions in instructional strategy: An example in physics. Cognition and Instruction, 1987 - Taylor \& Francis

[19] Schnotz, W. "An integrated model of text and picture comprehension."The Cambridge handbook of multimedia learning (2005): 49-69.

[20] Latour, B. Pandora's hope: essays on the reality of science studies. Harvard University Press, 1999.

[21] Izquierdo-Aymerich, M. \& Adúriz-Bravo, A. Epistemological foundations of school science. - Science \& Education, Kluwer Academic Publishers. Printed in the Netherlands. Pg. 23, 2003.

[22] Kuhn, T. The Structure of Scientific Revolution. Chicago. The University of Chicago. (1970). A Estrutura das Revoluções Científicas. Coleção Debates. Ed. Perspectiva, 1999.

[23] Izquierdo-Aymerich, M., Sanmartí, N. \& Spinet, M. Fundamentación Y Diseño De Las Prácticas Escolares De Ciencias Experimentales. Enseñanza De Las Ciencias, 17 (1), 45-59, 1999. 
[24] Ausubel, D. The facilitation of meaningful verbal learning in the classroom. Educational Psychologist. Volume 12, Issue 2, 1977.

[25] Duit, R. On the role of analogies and metaphors in learning science. Science Education, 75 (6), pp. 649-672, 1991.

[26] Flick, L. 'Where Concepts Meet Percepts: Stimulating Analogical Thought in Children', Science Education 75 (2), 215-230, 1991.

[27] Ingham, A. 'The Use of Analogue Models by Students of Chemistry at Higher Education Level', International Journal of Science Education 13 (2), 193-202, 1991.

[28] Clement, J. Using Bridging Analogies and Anchoring Intuitions to Deal with Students' Preconceptions in Physics. Journal of Research in Science Teaching, 30 (10), pp. 10411057, 1993.

[29] Glencoe Science. Physics, Principles and Problems. The CMGraw-Hill Companies, Inc. (2005).

[30] Johnson-Laird, P. N. Mental Models. 6th Edition. Printed in USA. Cognitive Science Series, 1995.

[31] Johnson-Laird, P. N. Modelos mentales en ciencia cognitiva. NORMAN, D. A. Perspectivas de la ciencia cognitiva. Barcelona: Ediciones Paidós, p. 179 - 231, 1987.

[32] Moreira, M. A., Greca, I. M.; and Palmero, M. L. R. Modelos Mentales Y Modelos Conceptuales. En La Enseñanza \& Aprendizaje de Las Ciencias 13 (Mental models and conceptual models in the teaching \& learning of science). Revista Brasileira de Investigação em Educação em Ciências 2.3 (2002): 84-96.

[33] Nersessian, N. J. How do Scientist Think? Capturing the dynamics of Conceptual Change in Science. Cognitive models of science, pg. 3, 1992.

[34] Gilbert, J. K. and Swift, D. J. - Towards a lakatosian analysis of the piagetian and alternative conceptions research programs. Science Education Volume 69, Issue 5, pages 681696, October 1985.

[35] HAMPSON, P. J. and MORRIS, P. E. Understanding cognition. Cambridge, MA: Blackwell Publishers Inc 1996.

[36] Moreira, M. A. Modelos Mentais. Investigações em Ensino de Ciências - V 1 (3), pp. 193-232, 1996.

[37] Bent, H. Uses (and abuses) of models in teaching chemistry. Journal of Chemical Education, 61, 774-777, 1984.
[38] Gentner, D., and D. Gentner. "Flowing waters or teeming crowds: Mental models of electricity (pp. 99-129)." Mental models. Hillsdale, NJ: Lawrence Erlbaum Associates, 1983.

[39] Courant, R. and H. Robbins - What is mathematicas? Oxford Univ. Press, Oxford. 1961

[40] Ponte, J. P. (1992) - Concepções dos Professores de Matemática e Processos de Formação. Educação matemática: Temas de investigação (pp. 185-239). Lisboa: Instituto de Inovação Educacional.

[41] Ernest, P. (1994). The philosophy of mathematics and the didactics of mathematics. Didactics of mathematics as a scientific discipline, Springer.

[42] Schwartz, J. (1978). Mathematics as a tool for economic understanding. In L. A. Steen (Ed.), Matehmatics today: Twelve informal essays. New York, NY: Springer.

[43] Ojose, B. (2008) - Applying Piaget's Theory of Cognitive Development to Mathematics Instruction. The Mathematics Educator, 2008, Vol. 18, No. 1, 26-30

[44] Souza, M. A. V. F. (2015) \& H. M. Guimarães - A formulação de problemas verbais de matemática: porquê e como. Quadrante, Vol. XXIV, No 2, 2015

[45] Ellis, A. B. (2007) - Connections Between Generalizing and Justifying. Journal of Research in Mathematics Education. Vol. 38, No 3, 194.

[46] Hanna, G. (2000) - Proof, Explanation And Exploration: An Overview. Educational Studies in Mathematics 44: 5-23, 2000

[47] NCTM (2009). Princípios e Normas para a Matemática Escolar. Lisboa: APM, 2009.

[48] Dundar, S., B. Gokkurt, Y. Soylu - The efficiency of visualization through geometry at mathematics education: a theoretical framework. Social and Behavioral Sciences 46 (2012) $2579-2583$

[49] Reiss, K., Heinze, A. and A. Renkl - Reasoning And Proof: Methodological Knowledge as a Component of Proof Competence. ZDM Mathematics Education (2008) 40: 455467

[50] Poincaré, H. (1948). La creacion matematica. In M. Kline (Ed.), Matemáticas en el mundo moderno. Madrid: Blume.

[51] Bolter, Jay David. "Hypertext and the question of visual literacy." Handbook of literacy and technology: Transformations in a post-typographic world (1998): 3-13. 